\title{
Rapid review of multisystem inflammatory syndrome in paediatrics: What we know one year later
}

\author{
Megan Striha ${ }^{1}$, Rojiemiahd Edjoc ${ }^{1 *}$, Natalie Bresee ${ }^{2}$, Nicole Atchessi ${ }^{1}$, Lisa Waddell ${ }^{3}$, \\ Terri-Lyn Bennett ${ }^{4}$, Emily Thompson ${ }^{1}$, Maryem El Jaouhari', Samuel Bonti-Ankomah ${ }^{1}$
}

\begin{abstract}
Background: Multisystem inflammatory syndrome in children (MIS-C) associated with coronavirus disease 2019 (COVID-19) is an emerging condition that was first identified in paediatrics at the onset of the COVID-19 pandemic. The condition is also known as pediatric inflammatory multisystem syndrome temporally associated with severe acute respiratory syndrome coronavirus 2 (PIMS-TS or PIMS), and multiple definitions have been established for this condition that share overlapping features with Kawasaki Disease and toxic shock syndrome.

Methods: A review was conducted to identify literature describing the epidemiology of MIS-C, published up until March 9, 2021. A database established at the Public Health Agency of Canada with COVID-19 literature was searched for articles referencing MIS-C, PIMS or Kawasaki Disease in relation to COVID-19.
\end{abstract}

Results: A total of 195 out of 988 articles were included in the review. The median age of MIS-C patients was between seven and 10 years of age, although children of all ages (and adults) can be affected. Multisystem inflammatory syndrome in children disproportionately affected males (58\% patients), and Black and Hispanic children seem to be at an elevated risk for developing MIS-C. Roughly $62 \%$ of MIS-C patients required admission to an intensive care unit, with one in five patients requiring mechanical ventilation. Between $0 \%$ and $2 \%$ of MIS-C patients died, depending on the population and available interventions.

Conclusion: Multisystem inflammatory syndrome in children can affect children of all ages. A significant proportion of patients required intensive care unit and mechanical ventilation and $0 \%-2 \%$ of cases resulted in fatalities. More evidence is needed on the role of race, ethnicity and comorbidities in the development of MIS-C.
This work is licensed under a Creative Commons Attribution 4.0 International License.

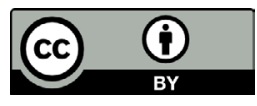

Affiliations

${ }^{1}$ Health Security and Regional Operations Branch, Public Health Agency of Canada, Ottawa, ON

${ }^{2}$ Children's Hospital of Eastern Ontario, Ottawa, ON

${ }^{3}$ National Microbiology Laboratory, Public Health Agency of Canada, Winnipeg, MB

${ }^{4}$ Centre for Surveillance and Applied Research, Public Health Agency of Canada, Ottawa, ON

\section{*Correspondence: rojiemiahd.edjoc@phac-aspc. gc.ca}

Suggested citation: Striha M, Edjoc R, Bresee N, Atchessi N, Waddell L, Bennett T-L, Thompson E, El Jaouhari M, Bonti-Ankomah S. Rapid review of multisystem inflammatory syndrome in paediatrics: What we know one year later. Can Commun Dis Rep 2021;47(11):466-72. https://doi.org/10.14745/ccdr.v47i11a04

Keywords: multisystem inflammatory syndrome in children, pediatric multisystem inflammatory syndrome, COVID-19, MIS-C, PIMS, PIMS-TS

\section{Introduction}

On March $11^{\text {th }}, 2020$ the World Health Organization declared a global pandemic of the severe acute respiratory syndrome coronavirus 2 (SARS-CoV-2). Soon after, in April 2020, multisystem inflammatory syndrome in children (MIS-C) associated with SARS-CoV-2 virus was identified in the United Kingdom (UK) (1). Multisystem inflammatory syndrome in children is an acute illness that is characterized by immune dysregulation with multisystem involvement and severe symptoms typically requiring hospitalization. The syndrome is thought to occur in children two to six weeks following infection with SARS-CoV-2 (2).

The syndrome is also known as pediatric inflammatory multisystem syndrome temporally associated with SARS-CoV-2 (PIMS-TS or PIMS). Multiple definitions have been established for this condition, including by the World Health Organization (3), 
United States (US) Centers for Disease Control and Prevention (4), the Royal College of Paediatrics and Child Health in the UK (5) and the Canadian Paediatric Society $(6,7)$. The definitions, which are similar but not identical, are provided in Appendix A.

There is no definitive diagnostic test for MIS-C and MIS-C is considered a separate but similar clinical syndrome to Kawasaki Disease (complete, incomplete, atypical or shock syndrome), toxic shock syndrome and macrophage activated syndrome (8).

\section{Current situation}

More than a year has elapsed since MIS-C was first identified during the ongoing coronavirus disease 2019 (COVID-19) pandemic and a large body of evidence is now available. This review aims to synthesize what is currently known and what is still unclear about the epidemiological characteristics of this emerging disease.

\section{Methods}

A database maintained by the Public Health Agency of Canada is populated daily with new COVID-19 literature and includes studies published since the start of the pandemic until March 9, 2021, in PubMed, Scopus, BioRxiv, MedRxiv, ArXiv, SSRN and Research Square. Articles were cross-referenced with the COVID-19 information centers centres run by Lancet, BMJ, Elsevier and Wiley. These COVID-19 studies were gathered in an Excel spreadsheet database and were searched to retrieve MIS-C literature.

Articles $(n=998)$ were screened for relevance and were included if epidemiological descriptions of MIS-C, PIMS, PIMS-TS or Kawasaki Disease related to COVID-19 were present. Articles $(n=803)$ were excluded if they were not available in English or French, they were off-topic, they were review article or they did not contain epidemiological data from MIS-C patients. In total, 195 articles were deemed relevant and included in this review (Figure 1). Multiple articles could potentially refer to the same cases, and therefore double counting is a limitation of this review.

\section{Results}

A total of 195 articles were included in this review. The vast majority of articles were cohorts (prospective $n=15$, retrospective $n=70$ or ambi-directional $n=4)$ and case reports $(n=101)$, with a minority being case-controls $(n=3)$ or natural experiments $(n=2)$.

Most articles originated in the US $(n=78)$ and the UK $(n=23)$, with a smaller number from India $(n=18)$ and European countries (France $n=12$, Italy $n=10$, Spain $n=7$ ). There were
Figure 1: Article exclusion tree

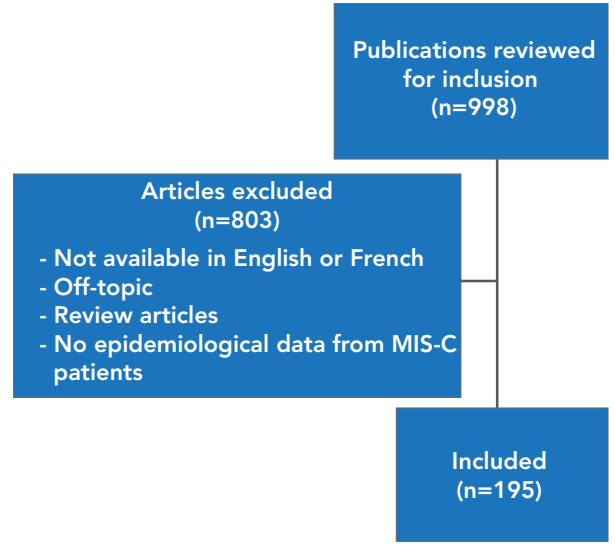

Abbreviation: MIS-C, multisystem inflammatory syndrome in children

far fewer studies from Africa (South Africa $n=2$, Algeria $n=1$, Nigeria $n=1$, Egypt $n=1$ ) and Asia (South Korea $n=2$, Japan $n=1$, Indonesia $n=1$ ).

Case reports were summarized together (articles=101, MIS-C cases $=207$ ), as individual patient information was often available. The cohorts, case-controls and natural experiment articles were also summarized together and are referred to as cohorts in the results section (articles=94, MIS-C cases=4,630). Article summaries are available in Supplemental material.

\section{Age and sex}

In the cohort articles, 50 of $72(70 \%)$ articles reported the median age of MIS-C patients as between seven and 10 years (Figure 2). In addition, the median age of 184 patients reported in case reports was 8.8 years, ranging from one month to 20 years (23 cases did not have individual age data). However, MIS-C has been reported in all paediatric age groups, with wide ranges in many articles (Figure 3).

Figure 2: Median age of multisystem inflammatory syndrome in children cases presented in cohort articles $(n=72)$

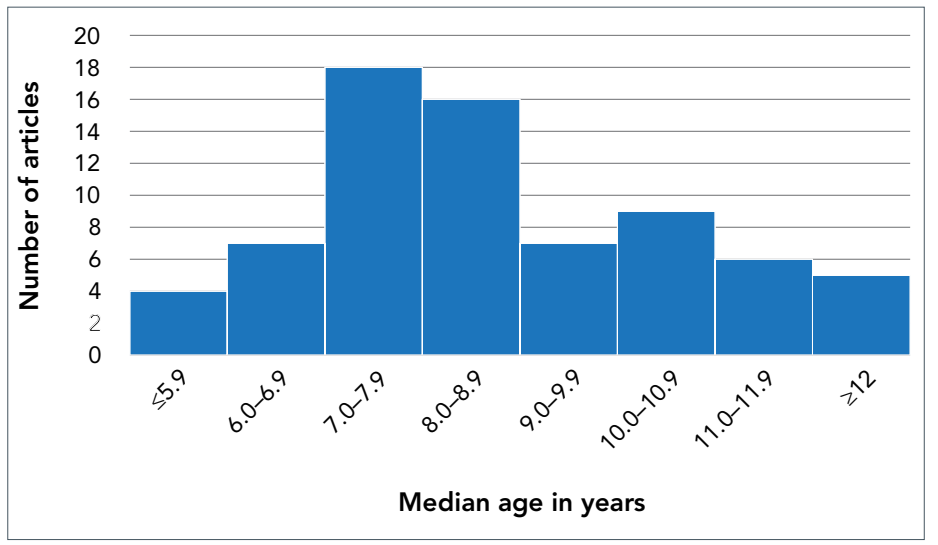


Figure 3: Age of multisystem inflammatory syndrome in children patients reported in case report articles $(n=101$, MIS-C cases $=185$ )

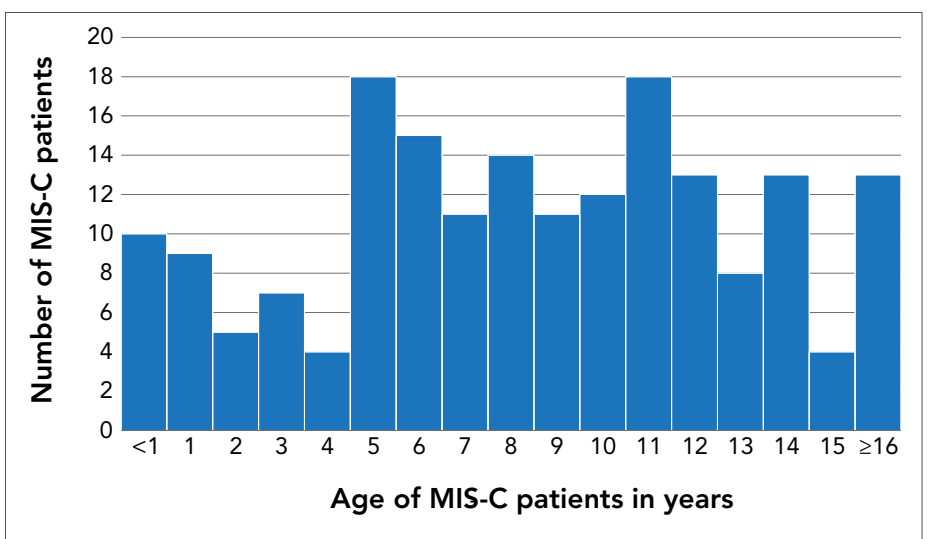

Abbreviation: MIS-C, multisystem inflammatory syndrome in children

More male than female MIS-C cases were identified in this review. Cohort articles that report on sex gave an overall average of $58 \%$ male, with 64 of 89 (72\%) reporting more male MIS-C cases than female. Additionally, there were 115 males out of 197 patients identified in case reports, for a total of $58 \%$ male (10 cases did not have sex data).

\section{Race, ethnicity and comorbidities}

The distribution of race, ethnicity and comorbidities in MIS-C cases is less clear than of age and sex. This is in part because of the varied general population of the geographies represented in the articles and in part due to issues with incomplete data collection. In addition, race and ethnicity are known to affect the likelihood of becoming infected with COVID-19 initially (9-13) and could also affect the likelihood of developing MIS-C subsequently (Figure 4). This is a complex relationship, which few articles have sought to disentangle.
Figure 4: Relationship ${ }^{a}$ between general population, COVID-19 and MIS-C cases

General
population
Abbreviations: COVID-19, coronavirus disease 2019; MIS-C, multisystem inflammatory syndrome
in children
a There is evidence that racial and ethnic minority groups are disproportionately affected by
COVID-19 (arrow 1). The effect of race and ethnicity on arrow 2 is less clear
In the United States, the US Centers for Disease Control and
Prevention states that, compared with White people, Black
people are 1.1 times more likely to be infected and 2.8 times
more likely to be hospitalized with COVID-19, while Hispanic
people are 2.0 times more likely to be infected and 3.0 times
more likely to be hospitalized with COVID-19 (10). Many factors
have been identified as causes of these disparities. Racial and
ethnic minorities face several issues, including discrimination,
access to health care and income inequality. Black and Hispanic
people are also more likely to live in crowded housing and
have a higher likelihood of being frontline workers, leading to
higher risk of COVID-19 infections (11). These disparities and the
resulting high burden of COVID-19 cases may partially or wholly
explain the disproportionately high rates of MIS-C sometimes
reported among Black and Hispanic populations.

Three articles describing large cohorts took a closer look at the relationship between race, ethnicity and MIS-C cases (Table 1). Overall, one article found a disproportionately high incidence of MIS-C in Black and Hispanic children compared to White children (incidence rate ratio of 3.15 and 1.70 respectively) (14). If race and ethnicity play no role in the development of MIS-C after COVID-19 (arrow 2 in Figure 4), the expectation is that a proportionate number of children of every race and ethnicity will develop MIS-C after COVID-19. Three studies suggest that this is not the case, and that Black children are overrepresented among MIS-C cases when compared to those hospitalized with COVID-19 (14-16). Conversely, Hispanic children are

Table 1: Comparison of the racial and ethnic composition of the general population, hospitalized coronavirus disease 2019 cases and multisystem inflammatory syndrome in paediatric cases

\begin{tabular}{|c|c|c|c|c|}
\hline \multirow{2}{*}{\multicolumn{2}{|c|}{ Racial and ethnic composition }} & \multicolumn{3}{|c|}{$\%$ Composition } \\
\hline & & \multirow{2}{*}{$\begin{array}{l}\text { Lee et al. (14) } \\
\qquad(\mathrm{US})^{\mathrm{a}} \\
\qquad(\mathrm{n}=182)\end{array}$} & \multirow{2}{*}{$\begin{array}{l}\text { Feldstein et al. (15) } \\
\qquad \begin{array}{c}(\mathrm{US})^{\mathrm{b}} \\
(\mathrm{n}=421)\end{array}\end{array}$} & \multirow{2}{*}{$\begin{array}{c}\text { Swann et al. (16) } \\
\text { (UK) } \\
(n=651)\end{array}$} \\
\hline \multirow{4}{*}{$\begin{array}{l}\text { Black } \\
\text { children }\end{array}$} & ercentage of Black children in the general naediatric nonulat & & & \\
\hline & 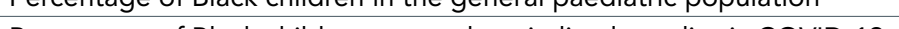 & & & IN/A \\
\hline & $\begin{array}{l}\text { Percentage of Black children among hospitalized paediatric COVID-19 } \\
\text { cases }\end{array}$ & $19.9 \%$ & $21.5 \%$ & $7.4 \%$ \\
\hline & Percentage of Black children among MIS-C cases & $34.4 \%$ & $32.3 \%$ & $17.3 \%$ \\
\hline \multirow{3}{*}{$\begin{array}{l}\text { Hispanic } \\
\text { children }\end{array}$} & Percentage of Hispanic children in the general paediatric population & $35.6 \%$ & $\mathrm{~N} / \mathrm{A}$ & $\mathrm{N} / \mathrm{A}$ \\
\hline & $\begin{array}{l}\text { Percentage of Hispanic children among hospitalized paediatric } \\
\text { COVID-19 cases }\end{array}$ & $40.0 \%$ & $45.4 \%$ & N/A \\
\hline & Percentage of Hispanic children among MIS-C cases & $29.8 \%$ & $35.8 \%$ & N/A \\
\hline \multirow{3}{*}{$\begin{array}{l}\text { White } \\
\text { children }\end{array}$} & Percentage of White children in the general paediatric population & $26.1 \%$ & $\mathrm{~N} / \mathrm{A}$ & N/A \\
\hline & $\begin{array}{l}\text { Percentage of White children among hospitalized paediatric COVID-19 } \\
\text { cases }\end{array}$ & $13.8 \%$ & $18.4 \%$ & $51.2 \%$ \\
\hline & Percentage of White children among MIS-C cases & $12.8 \%$ & $11.7 \%$ & $30.8 \%$ \\
\hline
\end{tabular}

Abbreviations: COVID-19, coronavirus disease 2019; MIS-C, multisystem inflammatory syndrome in children; UK, United Kingdom; US, United States

New York, New York

b 31 states across US 
underrepresented among MIS-C cases when compared to those hospitalized with COVID-19 $(14,15)$. There is also some evidence that White children are underrepresented among MIS-C cases when compared to those hospitalized with COVID-19 $(15,16)$.

The most commonly reported comorbidities in the articles of children with MIS-C were asthma and obesity. However, one article found that MIS-C patients were more likely to have no comorbidities than acute COVID-19 patients (15), while a second found that MIS-C patients are slightly more likely to be obese than those in the general population (17). Overall, the evidence on comorbidities in MIS-C patients is relatively underdeveloped.

\section{Outcomes}

A large proportion of MIS-C patients (generally more than half) were admitted to an intensive care unit (ICU) or pediatric intensive care unit (PICU). In articles where ICU/PICU admission was not required as part of the study design, 56 cohort articles reported $62 \%$ of patients were admitted to ICU (Figure 5), while 80 case reports stated $78 \%$ of patients were admitted to ICU.

Figure 5: Percent of cases of multisystem inflammatory syndrome in paediatric patients admitted to ICU/PICU in cohort articles where ICU/PICU admission was not required by the study design $(n=56)$

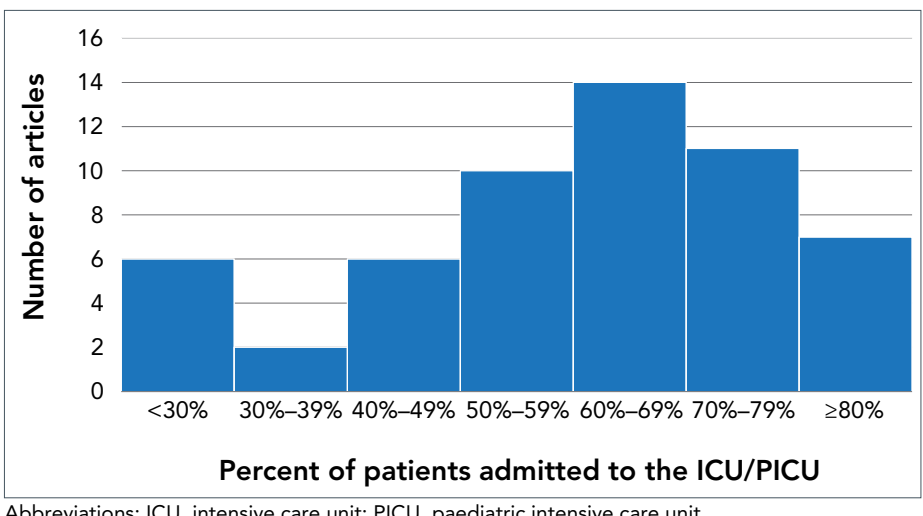

In addition, approximately one in five MIS-C patients required intubation. In articles where ICU admission was not required as part of the study design, 45 cohort articles reported $22 \%$ of patients were intubated (Figure 6). In addition, in 14 cohort studies that did require ICU/PICU admission, $32 \%$ of patients were intubated. Finally, 76 case reports stated $34 \%$ of patients required intubation.

Generally, approximately $2 \%$ of MIS-C patients died. In 72 cohort articles that reported on outcomes, $2.0 \%$ of all patients died ( $n=78 / 3,977$ cases), although 48 of 72 articles reported no deaths at all. In 88 case reports, $6.4 \%$ of all patients died. The case reports tend to highlight unique or more serious cases, which may explain why the overall mortality rate in these articles was much higher than in the cohort articles.
Figure 6: Percent of cases of multisystem inflammatory syndrome in paediatrics patients that were intubated in cohort articles where the study design did not require ICU/PICU admission $(n=45)$

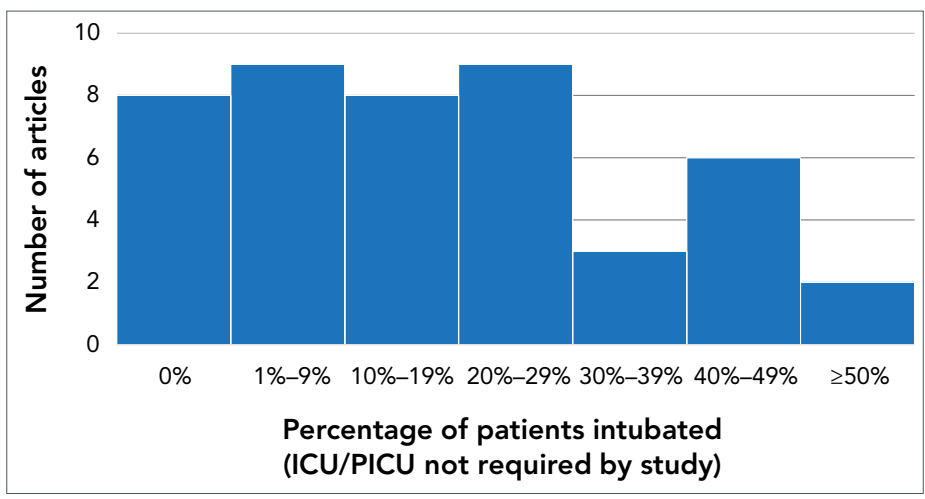

Abbreviations: ICU, intensive care unit; $\mathrm{PICU}$, paediatric intensive care unit

\section{Discussion}

There is a growing body of evidence outlining the epidemiological characteristics of MIS-C patients. It is clear that MIS-C affects children of all ages, with median age reported between seven and 10 years in $70 \%$ of articles. There seems to be proportionally fewer cases reported in children and young adults 16 years and older relative to rates of COVID-19 infection in these groups, but this may be due to many of the articles being based on work in paediatric hospitals. When compared with rates of COVID-19 cases, older teenagers and young adults in the US are more likely to be infected (or tested and identified as cases) than children, contrary to what has been reported about MIS-C rates so far (18).

The overrepresentation of male MIS-C cases is not seen in the rates of COVID-19 in children. In the US, male and female children are affected by COVID-19 roughly equally, with slightly higher rates in girls (18). However, the slight overrepresentation of male children is also seen in Kawasaki Disease, a closely related condition that has a better-developed body of evidence available. There is some suggestion that the male overrepresentation is due to genetic factors in Kawasaki Disease (19), which could be explored further to determine if this is also the case for MIS-C.

In regard to race and ethnicity, it is well established that racial and ethnic minority groups are disproportionately burdened by COVID-19 cases because of sociodemographic and other related factors (11-13). There is some evidence that Black and Hispanic children are disproportionately affected by MIS-C as well. The evidence presented here is from only two US and one UK study, and further studies are needed to verify these observations. 
There is some evidence from studies on Kawasaki Disease that suggest genetic factors might play a role, with certain Asian groups being overrepresented amongst Kawasaki cases (20). Exploration of similar mechanisms in MIS-C would provide further insight.

In addition, comorbidities were inconsistently reported and are interrelated with other epidemiological factors, such as race and ethnicity. It is thus less clear how obesity, asthma and other comorbidities contribute to the development of MIS-C.

Finally, it is clear that MIS-C is a syndrome that causes serious symptoms that require hospitalization and often admission to an ICU or PICU. Access to adequate care, including intubation in severe cases, is critical in the treatment of MIS-C.

\section{Conclusion}

Multisystem inflammatory syndrome in children can affect children of all ages, with a median age most commonly reported between seven and 10 years. Males were more often affected ( $58 \%$ of cases). Many patients, often more than half, were admitted to the ICU or PICU, with a fifth requiring intubation. Between $0 \%$ and $2 \%$ of MIS-C patients died, depending on the context and available treatment. More evidence is needed on the role of race, ethnicity and comorbidities in the development of MIS-C. Future avenues of study include surveillance reports targeting incidence, along with studies on sequelae.

\section{Authors' statement}

MS - Methodology, investigation, writing-original draft

$\mathrm{RE}$ - Conceptualization, writing-review and editing, supervision

NB - Writing-review and editing

LW - Writing-review and editing

T-LB - Writing-review and editing

ET - Writing-review and editing

MEJ - Writing-review and editing

SB-A - Writing-review and editing

\section{Competing interests}

None.

\section{Acknowledgements}

We would like to acknowledge the work of the Emerging Science Group for allowing us to collaborate with them on this important issue.

\section{Funding}

None.

\section{Supplemental material}

Summary of evidence on multisystem inflammatory syndrome in children $(n=195)$

\section{References}

1. European Centre for Disease Prevention and Control. Paediatric inflammatory multisystem syndrome and SARS-CoV-2 infection in children Paediatric inflammatory multisystem syndrome and SARS-CoV-2 infection in children ECDC; 2020 (accessed 2020-11-27). https://www.ecdc. europa.eu/sites/default/files/documents/covid-19-riskassessment-paediatric-inflammatory-multisystem-syndrome15-May-2020.pdf

2. Centers for Disease Control and Prevention. Reporting Multisystem Inflammatory Syndrome in Children (MIS-C). Atlanta, GA: CDC; 2020 (accessed 2021-04-26).

https://www.cdc.gov/mis-c/pdfs/hcp/MIS-Children-HandoutFINAL.pdf

3. World Health Organization. Multisystem inflammatory syndrome in children and adolescents temporally related to COVID-19. Geneva, Switzerland: WHO; 2020 (accessed 2020-11-27). https://www.who.int/news-room/ commentaries/detail/multisystem-inflammatory-syndromein-children-and-adolescents-with-covid-19

4. Centers for Disease Control and Prevention. Information for Healthcare Providers about Multisystem Inflammatory Syndrome in Children (MIS-C). Atlanta, GA; CDC: 2020 (accessed 2020-11-27). https://www.cdc.gov/mis-c/hcp/

5. Royal College of Paediactrics and Child Health. Paediatric multisystem inflammatory syndrome temporally associated with COVID-19 (PIMS) - guidance for clinicians. London, UK: RCPCH; 2020 (accessed 2020-11-27). https://www. rcpch.ac.uk/resources/paediatric-multisystem-inflammatorysyndrome-temporally-associated-covid-19-pims-guidance

6. Canadian Paediatric Society. Case definition for COVID-19 study. Ottawa (ON): CPSP; 2020 (accessed 2021-05-10). https://www.cpsp.cps.ca/uploads/studies/COVID-19-casedefinition-rev-06-2020.pdf

7. Canadian Paediatric Society. Berard R, Scuccimarri R, Haddad E, Morin M, Chan K, Dahdah N, McCrindle BW, Price VE, Yeung RSM, Laxer RM, Acute Care Committee. Paediatric inflammatory multisystem syndrome temporally associated with COVID-19 (spring 2021 update). Ottawa (ON): CPS; 2020 (updated 2021-03-21). https://cps.ca/en/ documents/position/pims

8. Nakra NA, Blumberg DA, Herrera-Guerra A, Lakshminrusimha S. Multi-System Inflammatory Syndrome in Children (MIS-C) Following SARS-CoV-2 Infection: Review of Clinical Presentation, Hypothetical Pathogenesis, and Proposed Management. Children (Basel) 2020;7(7):69. DOI PubMed 
9. Public Health Ontario. Enhanced Epidemiological Summary. COVID-19 in Ontario - A Focus on Diversity. Toronto (ON): PHO; (updated 2020-05-14). https:// www.publichealthontario.ca/-/media/documents/ncov/ epi/2020/06/covid-19-epi-diversity.pdf?la=en

10. Information for Healthcare Providers about Multisystem Inflammatory Syndrome Risk for COVID-19 Infection, Hospitalization, and Death By Race/Ethnicity. Atlanta, GA, CDC; 2021 (accessed 2021-04-27). https://www.cdc.gov/ coronavirus/2019-ncov/covid-data/investigations-discovery/ hospitalization-death-by-race-ethnicity.html

11. Information for Healthcare Providers about Multisystem Inflammatory Syndrome. Health Equity Considerations and Racial and Ethnic Minority Groups. Atlanta, GA: CDC; 2021 (accessed 2021-05-07). https://www.cdc.gov/ coronavirus/2019-ncov/community/health-equity/raceethnicity.html

12. Escobar GJ, Adams AS, Liu VX, Soltesz L, Chen YI, Parodi SM, Ray GT, Myers LC, Ramaprasad CM, Dlott $\mathrm{R}$, Lee C. Racial Disparities in COVID-19 Testing and Outcomes : Retrospective Cohort Study in an Integrated Health System. Ann Intern Med 2021;174(6):786-93. DOI PubMed

13. Toronto Public Health. COVID-19: Status of Cases in Toronto - City of Toronto. Toronto (ON): TPH; 2021 (accessed 2021-05-10). https://www.toronto.ca/home/ covid-19/covid-19-latest-city-of-toronto-news/covid-19status-of-cases-in-toronto/

14. Lee EH, Kepler KL, Geevarughese A, Paneth-Pollak R, Dorsinville MS, Ngai S, Reilly KH. Race/Ethnicity Among Children With COVID-19-Associated Multisystem Inflammatory Syndrome. JAMA Netw Open 2020;3(11):e2030280. DOI PubMed

15. Feldstein LR, Tenforde MW, Friedman KG, Newhams $M$, Rose EB, Dapul H, Soma VL, Maddux AB, Mourani PM, Bowens C, Maamari M, Hall MW, Riggs BJ, Giuliano JS Jr, Singh AR, Li S, Kong M, Schuster JE, McLaughlin GE, Schwartz SP, Walker TC, Loftis LL, Hobbs CV, Halasa NB, Doymaz S, Babbitt CJ, Hume JR, Gertz SJ, Irby K, Clouser KN, Cvijanovich NZ, Bradford TT, Smith LS, Heidemann SM, Zackai SP, Wellnitz K, Nofziger RA, Horwitz SM, Carroll RW, Rowan CM, Tarquinio KM, Mack EH, Fitzgerald JC, Coates BM, Jackson AM, Young CC, Son MBF, Patel MM, Newburger JW, Randolph AG; Overcoming COVID-19 Investigators. Characteristics and Outcomes of US Children and Adolescents with Multisystem Inflammatory Syndrome in Children (MIS-C) Compared with Severe Acute COVID-19. JAMA 2021;325(11):1074-87. DOI
16. Swann OV, Holden KA, Turtle L, Pollock L, Fairfield CJ, Drake TM, Seth S, Egan C, Hardwick HE, Halpin S, Girvan M, Donohue C, Pritchard M, Patel LB, Ladhani S, Sigfrid L, Sinha IP, Olliaro PL, Nguyen-Van-Tam JS, Horby PW, Merson L, Carson G, Dunning J, Openshaw PJ, Baillie JK, Harrison EM, Docherty AB, Semple MG; ISARIC4C Investigators. Clinical characteristics of children and young people admitted to hospital with covid-19 in United Kingdom: prospective multicentre observational cohort study. BMJ 2020;370:m3249. DOI PubMed

17. Godfred-Cato $S$, Bryant B, Leung J, Oster ME, Conklin L, Abrams J, Roguski K, Wallace B, Prezzato E, Koumans EH, Lee EH, Geevarughese A, Lash MK, Reilly KH, Pulver WP, Thomas D, Feder KA, Hsu KK, Plipat N, Richardson G, Reid H, Lim S, Schmitz A, Pierce T, Hrapcak S, Datta D, Morris SB, Clarke K, Belay E; California MIS-C Response Team. COVID-19-Associated Multisystem Inflammatory Syndrome in Children - United States, March-July 2020. MMWR Morb Mortal Wkly Rep 2020;69(32):1074-80. DOI PubMed

18. Leidman E, Duca LM, Omura JD, Proia K, Stephens JW, Sauber-Schatz EK. COVID-19 Trends Among Persons Aged 0-24 Years - United States, March 1-December 12, 2020. MMWR Morb Mortal Wkly Rep 2021;70(3):88-94. DOI PubMed

19. Kwon YC, Kim JJ, Yun SW, Yu JJ, Yoon KL, Lee KY, Kil HR, Kim GB, Han MK, Song MS, Lee HD, Ha KS, Sohn S, Ebata $R$, Hamada $H$, Suzuki $H$, Ito K, Onouchi $Y$, Hong YM, Jang GY, Lee JK; Korean Kawasaki Disease Genetics Consortium. Male-specific association of the FCGR2A His167Arg polymorphism with Kawasaki disease. PLoS One 2017;12(9):e0184248. DOI PubMed

20. Rowley $\mathrm{AH}$. Kawasaki disease: novel insights into etiology and genetic susceptibility. Annu Rev Med 2011;62:69-77. DOI PubMed 


\section{Appendix A: Definitions of multisystem inflammatory syndrome in children}

The definition of multisystem inflammatory syndrome (MIS-C) published by the World Health Organization (3) states:

- Children and adolescents 0-19 years of age with fever for more than three days

AND

- Two of the following:

- Rash or bilateral non-purulent conjunctivitis or mucocutaneous inflammation signs (oral, hands or feet)

o Hypotension or shock

- Features of myocardial dysfunction, pericarditis, valvulitis, or coronary abnormalities (including $\mathrm{ECHO}$ findings or elevated Troponin/NT-proBNP)

o Evidence of coagulopathy (by PT, PTT, elevated d-Dimers)

- Acute gastrointestinal problems (diarrhoea, vomiting, or abdominal pain)

AND

- $\quad$ Elevated markers of inflammation such as erythrocyte sedimentation rate (ESR), C-reactive protein (CRP), or procalcitonin

AND

- No other obvious microbial cause of inflammation, including bacterial sepsis, staphylococcal or streptococcal shock syndromes

AND

- $\quad$ Evidence of the coronavirus disease 2019 (COVID-19) (reverse transcription polymerase chain reaction (RT-PCR), antigen test or serology positive), or likely contact with patients with COVID-19

The case definition of MIS-C published by the United States Centers for Disease Control (4) states:

- An individual aged younger than 21 years presenting with fever (greater than $38.0^{\circ} \mathrm{C}$ for greater than or equal to 24 hours, or report of subjective fever lasting greater than or equal to 24 hours), laboratory evidence of inflammation, and evidence of clinically severe illness requiring hospitalization, with multisystem (more than two) organ involvement (cardiac, renal, respiratory, hematologic, gastrointestinal, dermatologic or neurological)

AND

- No alternative plausible diagnoses

AND

- $\quad$ Positive for current or recent severe acute respiratory syndrome coronavirus 2 (SARS-CoV-2) infection by RT-PCR, serology, or antigen test; or exposure to a suspected or confirmed COVID-19 case within the four weeks prior to the onset of symptoms
The definition of pediatric inflammatory multisystem syndrome (PIMS) released by the United Kingdome Royal College of Paediatrics and Child Health (RCPCH) (5) states:

- A child presenting with persistent fever, inflammation (neutrophilia, elevated CRP and lymphopenia) and evidence of single or multi-organ dysfunction (shock, cardiac, respiratory, renal, gastrointestinal or neurological disorder) with additional features. This may include children fulfilling full or partial criteria for Kawasaki disease

AND

- Exclusion of any other microbial cause, including bacterial sepsis, staphylococcal or streptococcal shock syndromes, infections associated with myocarditis such as enterovirus (waiting for results of these investigations should not delay seeking expert advice)

AND

- $\quad$ SARS-CoV-2 PCR testing may be positive or negative

The definition of PIMS released by the Canadian Paediatric Society $(6,7)$ states:

- Persistent fever (higher than $38.0^{\circ} \mathrm{C}$ for three or more days) and elevated inflammatory markers (CRP, ESR, or ferritin)

AND one of both of the following:

- Features of Kawasaki disease (complete or incomplete)

- Toxic shock syndrome (typical or atypical)

AND

- No alternative etiology to explain the clinical presentation AND

- Patients need not have positive SARS-CoV-2 status for consideration 